\title{
Question Generation as a Strategy for Advancing Intermediate- and Low-Achieving Students in Higher Education
}

\author{
Ester Aflalo ${ }^{1}$ \\ ${ }^{1}$ Hemdat Hadarom College of Education, Netivot, Israel \\ Correspondence: Ester Aflalo, Hemdat Hadarom College of Education, P.O.B. 412, Netivot 80200, Israel. Tel: \\ 972-8-993-7697. E-mail: ester@hemdat.ac.il
}

Received: November 19, 2020

Accepted: December 28, 2020

Online Published: January 13, 2021

doi:10.5430/irhe.v5n4p14

URL: https://doi.org/10.5430/irhe.v5n4p14

\begin{abstract}
Student question generation (SQG) is a teaching and learning strategy that promotes higher-order cognitive skills. The purpose of this study is to determine which students gain the most from SQG activities: Is it mainly those with strong academic achievements? The study took place over the course of six years, during which 171 preservice teachers in Israel generated, answered, and peer-evaluated questions at higher and lower orders of thinking. When their exam grades before and after the SQG intervention were checked, the intermediate- and low-achieving students showed the most significant improvement. These findings could contribute to a reassessment of commonly held attitudes about the ostensible inability of underachieving students to engage in higher-order thinking tasks.
\end{abstract}

Keywords: student question-generation, low-achieving students, higher-order-thinking questions, active learning

\section{Introduction}

Generating, solving, and evaluating questions are active tasks that promote various aspects of cognitive and metacognitive learning (Yu, Fu-Yun, 2012; Kelley, Chapman-Orr, Calkins, \& Lemke, 2019; Kay, Hardy, \& Galloway, 2020). Despite the importance of student question generation (SQG) and its associated activities, teachers do not tend to include it in their teaching, instead focusing students' attention on simply answering questions.

This study is the continuation of a previous study among science preservice teachers that proposed a model for integrating SQG activities into academic courses. That study also presented findings indicating that the SQG model helped to improve the students' ability to cope with higher-order-thinking questions (Aflalo, 2018).

A concise version of the model for integrating SQG activities, described at length in the previous study, is included as an appendix to this study. Broadly expressed, the model integrates three different activities: (1) question-generation by the students (2) students answering peer-generated questions; and (3) peer assessment of other students' questions.

The study described below took place over a six-year period. The research population was divided into four groups differentiated by their level of achievement before the SQG intervention. The main research question was: which groups of students gain the most from SQG-is it mainly the high-achievers, or do lower-achieving students also benefit?

It is worth noting that most studies about low-achieving students are performed among primary- or secondary-school pupils and not among college students, as is the case in the current study. The study is also significant in that, while many studies have dealt with inquiry-based learning and problem-solving, few have addressed SQG and, among those dealing with SQG, very few examine its effect on students of different levels of achievement.

\section{Literature Reivew}

\subsection{Student Question Generation}

Questioning is fundamental in learning; students' questions play a crucial role in meaningful learning and in their motivation for learning. The types and levels of questions may be classified commensurate with the order of thinking that is needed to answer them. One of the most commonly accepted classifications is Bloom's Taxonomy (Bloom, 1956), which yields a hierarchy of different kinds of questions ranging from knowledge questions, which reflect the lowest order of thinking, to comprehension, application, analysis, synthesis, and evaluation questions at the higher 
levels. Decades later, Anderson and Krathwohl (2001) revised the taxonomy by emphasizing differences among the cognitive processes. Other differentiations are broader in their reference, offering a general classification of higher-order and lower-order questions. Papinczak et al. (2012), for example, sorted questions into two groups: confirmation and transformation. Confirmation questions are meant to elucidate information and define and explain concepts, whereas transformation questions involve reconstruction and reorganization of the student's comprehension. Transformation questions are considered examples of higher-order-thinking; they include, for example, Bloom, Anderson, and Krathwohl's application, analysis, synthesis, and evaluation questions.

The pedagogical value and importance of student question generation (SQG) is firmly based on empirical findings. A comprehensive analysis of 109 empirical studies on SQG, conducted in numerous disciplines and across all age groups (from primary school to college), yielded a widespread consensus on SQG's positive effects on learning (Yu, Fu-Yun, 2012). For example, one extensive study among science students at three different universities in Britain examined the effect of three student activities associated with multiple-choice questions: answering questions, generating questions, and examining and commenting on peers' questions. A significant positive correlation was found between these activities and exam grades when all three activities took place (Hardy et al., 2014). Similarly, a study of tenth-grade science pupils found that those who practiced question-generation improved their questioning ability as well as their academic achievements. Moreover, the findings showed that question-generating skills can be used as an alternative method for assessment, particularly in respect of higher-order thinking (Dori \& Herscovitz, 1999; Offerdahl \& Montplaisir, 2014). Similarly, Koch and Eckstine (1991) found that college physics students improved their reading comprehension when they were taught question-generation skills. Learning these skills stimulated their self-awareness of difficulties in reading comprehension and may have served as an exercise in self-regulated learning. Recent study on more than 3,000 students, across six large undergraduate courses (in physics, chemistry and biology) in three research-intensive UK universities showed a positive association between their academic achievement and the practice of generating and answering multiple-choice questions (Kay, Hardy, \& Galloway, 2020).

Research has found that students who invoke self-regulated learning processes refine their learning skills and develop critical thinking (Nguyen \& Ikeda, 2015; Stefanou, Stolk, Prince, Chen, \& Lord, 2013). In this context, question generation is an important metacognitive strategy that focuses students' attention on content and on central ideas, helping them develop critical thinking, the capacity for self-critique, and creativity (Chin \& Brown, 2002; Rothstein \& Santana, 2011). Interestingly, one study compared the effect on students of answering questions versus generating questions by examining their academic achievements and cognitive and metacognitive strategies. This study found no differences in academic achievements between students who answered questions and those who generated them; both activities were found equally effective. However, students who engaged in generating questions exhibited significantly higher-level cognitive strategies and metacognitive skills. They were more aware of their learning process, better able to critique their own work and self-assess their progress, and more willing to change (Yu, Fu-Yun \& Liu, 2008).

Although most studies demonstrate the value of SQG in the advancement of learning, little has been done to incorporate this activity into scholastic settings. Many lessons tend to be teacher-controlled monologues. Students in class ask few questions (Nystrand, Wu, Gamoran, Zeiser, \& Long, 2003) and most of their queries are basic knowledge questions that entail regurgitation of information (Chin \& Brown, 2002; Middlecamp \& Nickel, 2005). Particularly in higher education, students focus on questions that teachers ask or that are harvested from textbooks. Self-generated questioning, foremost the kind that involves higher-order thinking, is a process that most students practice only to a limited extent (Dori \& Herscovitz, 1999; Yu, Fu - Yun \& Chen, 2014).

Several explanations for students' limited question-generation have been proposed. Teachers who do not feel confident in the subject matter tend to suppress questioning. Furthermore, class atmosphere, pupils' fear of answering incorrectly, and teacher-pupil relations all influence questioning (Dillon, 1988). The number and type of questions that students ask depend on numerous additional factors such as the students' age, experience, and skills, their interest in the subject studied, and their proficiency in the subject, as well as the overall nature of the subject (Shodell, 1995).

\subsection{Low-Achieving Students and Higher-Order Thinking}

Nurturing higher-order thinking among students of all ages and at all levels is one of the most important goals in education (So, Seah, \& Toh-Heng, 2010; Yang, van Aalst, Chan, \& Tian, 2016). Many teachers, however, believe that tasks entailing higher-order thinking are suited mainly to high-achieving students and are beyond the reach of low achievers whose command of the basic information is weak (Raes, Schellens, \& De Wever, 2014; Zohar, \& Alboher 
Agmon, 2018; Zohar, Degani, \& Vaaknin, 2001). Fundamental to these conventional perceptions among teachers is the idea that knowledge-building is hierarchical. Namely, only after knowledge of the subject is mastered can students advance to tasks of higher cognitive orders of comprehension or application in the same subject. Due to this stepwise conception of knowledge-building, low-achieving pupils are often only assigned low-cognitive-level tasks (Shepard, 1991; Teo, \& Goh Wee, 2019).

However, developments in understanding how knowledge is built have blurred the hierarchy. These new insights emphasize that comprehension and thinking must occur at all levels of learning, including when acquiring basic knowledge. It has been claimed that the traditional concept, by which thinking and understanding can take place only after learning the foundation, can no longer play a leading role in teaching and that the advancement of thinking must be applied in all learning and to all students (Bransford, Brown, \& Cocking, 2000; Bruer, 1993).

Low-achieving students often have learning difficulties (Zohar \& Dori, 2003), limited learning skills, and poor self-image (Hacker, Bol, Horgan, \& Rakow, 2000). One of the key questions in education concerns the extent to which learning strategies that entail high-level cognitive skills can contribute to these students. Motivating students on different levels to contend successfully with higher-order thinking is certainly a challenge for teachers. Several studies, however, show that it is possible. White and Fredrickson (1998), for example, demonstrated that both high-achieving and low-achieving students gain from inquiry-based learning. They found that assessment by means of a structured portfolio had a positive effect on students' comprehension and that this effect was even stronger among low-achievers.

Zohar and Dori (2003) reinforced these findings by showing the favourable effect of cooperative inquiry-based learning on the performance of both high-achieving and low-achieving students. In one of their studies on high-school students, they demonstrated that low-achievers profit more significantly from reflective inquiry than do their high-achieving peers. Raes et al. (2014) found that online inquiry-based learning contributed to all pupils but contributed more to the advancement of low-achievers. Similarly, Kiuhara et al. (2020) presented that students with mathematics learning disability demonstrated greater gains in scores compared to their nondisabled peers after an intervention in which they learned to construct written arguments to develop their fraction knowledge.

Studies among college students show that even at this stage of schooling, high-thinking-level tasks are effective and contribute to students at all levels. Chiu and Cheng (2017), investigating the effect of active learning classrooms on university students in Hong Kong, found that those with high, intermediate, and low achievements all gained from active learning. The students' creativity levels improved irrespective of their academic achievements. Kogan and Laursen (2014) showed that mathematics students at four colleges made more progress in courses that employed inquiry-based learning than they did in other courses, with the strongest effect found among low achievers.

A few studies, mostly performed in primary and secondary schools, looked into the direct effect of SQG activities on students at different levels. Kaya (2015), for example, reported that without practicing SQG, high-achieving pupils at a primary school generated more questions, and of a higher order of thinking, than did low-achieving peers. However, Yerrick (2000) showed that underachieving high-school students who had lengthy histories of failure in school and were involved in generating questions and designing an experiment underwent meaningful changes in their comprehension of scientific-inquiry processes and the nature of science. A recent study on middle school students found that SQG promote the reading and comprehension ability of students with disabilities (Styevens et al. 2020).

The current study is one of the few that looks into the effect of SQG activities on college students at various levels. In previous study, it was found that practice in generating, answering, and assessing questions helps to improve the achievements of some college students (Aflalo, 2018). The current study asks who gains more from these activities - is it mainly high achievers, or do low achievers also profit?

\subsection{Research Questions}

1. Does practice in generating, answering, and assessing questions improve overall exam grades among each of the four groups of students - low, intermediate, good, and very good achievements - and, if so, to what extent?

2. Does practice in generating, answering, and assessing questions help to improve grades on higher-order questions within each of the four groups of students - and, if so, to what extent?

\section{Methodlogy}

\subsection{Research Approach}

The research is based on comparing exam grades pre- and post-intervention. The intervention consisted of students 
engaging in generating, answering, and peer-assessing questions in a college cell-biology course.

\subsection{Participants}

The research population comprised nine classes of science-education college students who met the same college admission conditions. All students took a cell-biology course at two academic education colleges in Israel. Both colleges are located in the south of Israel, are attended mainly by female students, and have very similar science-education curricula. Class-size ranged from 15 to 27 , and a total of 171 students participated in the study-152 women and 19 men, with an average age of 21.9 years. All of the students took the same course syllabus with the same lecturer, who had approximately twenty-two years of teaching experience.

\subsection{The Research Process}

The study was conducted over a period of six academic years in 2010-2016. The cell-biology course was taught to each of the nine classes in two terms, one from October to January and the other from March to June. Lessons in each course were given once a week for two hours - a total of fifty-six hours per course, with fourteen lessons per term. In the first term, the students did not engage in question generation. In the last lesson of the first term, when time was set aside to study for the course exam, students were given examples of questions and an opportunity to ask questions about each topic studied during the term. Throughout the second term, the students engaged in question-generation activities as described in length in the previous study (Aflalo, 2018). A concise description of these activities is also attached to this study as an Appendix. In short, three activities were conducted: question generation, question answering, and peer assessment that took place in the following sequence: (1) class discussion of the types of questions and their classification; (2) a homework assignment to generate, answer, and assess questions; (3) class discussion of the homework assignment; (4) a group activity in class to generate, answer, and peer-assess the questions; (5) creation of a question bank.

Exams were used in order to examine the effect of the SQG activities: At the end of each term, the students were tested on the subject matter that was covered during the term. Each exam comprised approximately fifteen questions, most of which (around eleven) were closed confirmation questions involving knowledge and memory, and four (about 25 percent of the exam) were open transformation questions testing comprehension, application, or synthesis. All nine classes took exams that were very similar, with minor variations.

\subsection{Data Analysis}

After the first-term exams were checked, the students in all of the classes were sorted into four achievement groups: low, intermediate, good, and very good. Table 1 itemizes the range, distribution, and frequency of each group's grades. To confirm the validity of the aforementioned grouping, the students' grades from three additional first-term courses were checked; all courses were in the Life Sciences- Zoology, General Botany and Human Physiology. For 142 students -83 percent of the total - a fit was found. Namely, the three grades of each of these students fell into the same range, as specified in Table 1. For the other 29 students, whose three grades fit into more than one range or one group, the three grades were averaged to determine the student's placement in the appropriate group.

Table 1. Grouping of students by pre-SQG grades

\begin{tabular}{lrrr}
\hline Group & \multicolumn{1}{l}{$\begin{array}{l}\text { Range of } \\
\text { grades }\end{array}$} & Frequency & Percent \\
\hline Low grades & $0-54$ & 23 & 13.5 \\
\hline Intermed. grades & $55-69$ & 40 & 23.4 \\
\hline Good grades & $70-84$ & 62 & 36.3 \\
\hline Very good grades & $85-100$ & 46 & 26.9 \\
\hline Total & 4 & 171 & 100.0 \\
\hline
\end{tabular}

Once the second-term exams were graded as well, the averages and standard deviations of each group's grades were calculated. The four higher-order-thinking questions were graded on a standard scale: points were given for the accuracy of the answers, a description of the explanation, and the reasoning. For each student and each group, the average grade and standard deviations for the higher-order-thinking questions were calculated. About 20 percent of all exams (34 exams, at least five from each group) were graded by an additional lecturer with extensive experience 
in cell biology. The correlation between the grades was high, at 87 percent.

To make sure that the students' apportionment into four achievement-based groups lent itself to reference and statistical comparison, an ANOVA test to examine inter-group variance was performed. Duncan post-hoc tests revealed significant differences among each of the four groups in regard to all independent variables (Table 2). By inference, then, the groups may be treated as distinct.

Table 2. ANOVA Test for inter-group variance

\begin{tabular}{|c|c|c|c|c|c|}
\hline Variables examined & Group & Mean & SD & $\mathrm{F}$ & Sig. \\
\hline \multirow[t]{5}{*}{ Overall grade before SQG } & Low grades & 41.17 & 11.05 & \multirow[t]{5}{*}{466.37} & \multirow[t]{5}{*}{.000} \\
\hline & Intermed. grades & 62.63 & 3.95 & & \\
\hline & Good grades & 76.35 & 4.32 & & \\
\hline & High grades & 89.52 & 3.04 & & \\
\hline & Total & 71.95 & 16.36 & & \\
\hline \multirow[t]{5}{*}{ Overall grade after SQG } & Low grades & 49.87 & 15.34 & \multirow[t]{5}{*}{87.41} & \multirow[t]{5}{*}{.000} \\
\hline & Intermed. grades & 68.20 & 8.40 & & \\
\hline & Good grades & 77.74 & 7.48 & & \\
\hline & High grades & 85.57 & 7.41 & & \\
\hline & Total & 73.87 & 14.47 & & \\
\hline \multirow{5}{*}{$\begin{array}{l}\text { Higher-order-thinking } \\
\text { question grades before } \\
\text { SQG }\end{array}$} & Low grades & 15.22 & 18.06 & \multirow[t]{5}{*}{49.75} & \multirow[t]{5}{*}{.000} \\
\hline & Intermed. grades & 29.75 & 22.31 & & \\
\hline & Good grades & 52.58 & 21.95 & & \\
\hline & High grades & 73.15 & 21.38 & & \\
\hline & Total & 47.75 & 29.20 & & \\
\hline \multirow{5}{*}{$\begin{array}{l}\text { Higher-order-thinking } \\
\text { question grades after SQG }\end{array}$} & Low grades & 31.52 & 26.35 & \multirow[t]{5}{*}{34.95} & \multirow[t]{5}{*}{.000} \\
\hline & Intermed grades & 51.50 & 21.19 & & \\
\hline & Good grades & 66.77 & 17.27 & & \\
\hline & High grades & 79.89 & 18.72 & & \\
\hline & Total & 61.99 & 25.28 & & \\
\hline
\end{tabular}

To compare the first-term and second-term grades of each student and each group, paired t-tests were performed between the overall exam grades in each term and between grades for the higher-order-thinking questions alone.

\section{Findngs}

\subsection{The Effect of SQG on the Overall Grades of the Student Groups}

Table 3 presents the comparison of each group's first-term exam grades-pre- SQG - and their second-term grades, post-SQG. It can be seen that neither students with good achievements nor those with very good-achievements showed a statistically significant improvement in their grades. However, a statistically significant rise in grades after engaging in question-generation was evident among both low-achieving and intermediate-achieving students. The increase in the average grade of the low-achieving group was particularly impressive-21 percent compared with 9 percent among the intermediate-achieving cohort. 
Table 3. Overall grades of student groups, before and after SQG

\begin{tabular}{llllll}
\hline Group & $\begin{array}{l}\text { Overall } \\
\text { grade before } \\
\text { SQG (SD) }\end{array}$ & $\begin{array}{l}\text { Overall } \\
\text { grade after } \\
\text { SQG (SD) }\end{array}$ & & & \\
& 41.17 & 49.87 & 4.58 & 22 & $.000^{* *}$ \\
& $(11.05)$ & $(8.40)$ & & & \\
\hline Low grades & 62.63 & 68.20 & 3.98 & 39 & $.000^{* *}$ \\
& $(4.32)$ & $(17.99)$ & & & \\
\hline Intermed. grades & 76.35 & 77.74 & 1.48 & 61 & .144 \\
\hline Good grades & $(18.72)$ & $(7.48)$ & & & \\
\hline Very good grades & 89.52 & 88.89 & 1.06 & 45 & .201 \\
& $(3.05)$ & $(6.41)$ & & & \\
\hline
\end{tabular}

\subsection{The Effect of SQG on Grades for Higher-Order-Thinking Questions Among the Student Groups}

A comparison of only the higher-order-question grades on the pre-SQG and post-SQG exams (Table 4) shows that most students' grades on the thinking questions rose significantly after the activity. In fact, only the group of highest achieving students showed no significant improvement. As with the overall grades, the strongest improvement was seen among the low-achieving group.

Table 4. Grades on higher-order questions, before and after SQG

\begin{tabular}{llllll}
\hline Group & $\begin{array}{l}\text { Grade before } \\
\text { SQG (SD) }\end{array}$ & $\begin{array}{l}\text { Grade after } \\
\text { SQG (SD) }\end{array}$ & & $d f$ & $p$ \\
\hline Low grades & 15.22 & 31.52 & 3.65 & 22 & $.000^{* *}$ \\
& $(11.06)$ & $(19.41)$ & & & \\
\hline Intermed. grades & 29.75 & 51.50 & 5.51 & 39 & $.000^{* *}$ \\
& $(22.33)$ & $(21.18)$ & & & \\
\hline Good grades & 52.58 & 66.77 & 5.34 & 61 & $.000^{* *}$ \\
& $(21.94)$ & $(17.27)$ & & & \\
\hline Very good grades & 73.15 & 79.89 & 1.69 & 45 & .098 \\
& $(21.37)$ & $(18.72)$ & & & \\
\hline
\end{tabular}

\section{Discussion and Implications}

In the previous study, it was found that activities in generating, answering, and peer-assessing questions do not conduce to significant improvement in the total grade of an entire student population. The current study, however, which segmented the students into groups that were differentiated by academic achievements, shows that specifically those with low and intermediate achievements improved their overall grades significantly. Furthermore, the analysis that compared students' achievements on higher-order-thinking questions alone reveals an especially significant and impressive improvement among students of intermediate and low achievements.

The overall findings of this study indicate that most students gained from the SQG activity. These findings reinforce Yu (2012), who, in a far-reaching overview, analysed numerous studies among students of different ages and different disciplines that reported a favourable effect of SQG. However, what was not examined in those studies and did come to light in the current study is that SQG activities are most beneficial to low- and intermediate-achieving students, improving their cognitive ability to contend with higher-order-thinking questions.

These encouraging findings reinforce the belief that all students should be encouraged to tackle higher-order tasks. Those with limited learning skills and poor self-image, however, need more systematic and structured support (Zohar \& Dori, 2003). Absent such reinforcement, the strong correlation between poor learning capabilities and low grades may persist (Proctor, Prevatt, Adams, Hurst, \& Petscher, 2006). Such assistance may take the form of active 
co-learning. In studies on the effect of shared inquiry-based learning, for example, the effect was found strongest among low-achievers (Kogan \& Laursen, 2014; Raes et al., 2014). Generating and assessing questions-particularly higher-order-thinking questions - entails complex thinking skills, much as inquiry-based learning does. Furthermore, the SQG activities in this study were conducted in groups and, as shown, even relatively brief practice with these activities had a dramatic effect on the students who had the greatest difficulties.

Thus, the low achieving students in the current study obtained the support that they needed chiefly through active learning and co-learning. Collaborative generation, answering, and assessment of questions, along with sharing of knowledge by means of a question bank, were especially useful anchors for these students. The question bank that was amassed from the full set of student-generated questions was instrumental in studying for exams and alleviating anxiety before exams, making similar exam questions easier to cope with (Aflalo, 2018). Interaction and co-learning confer valuable cognitive and metacognitive advantages. Question-generation forces students to attain strong command of the material; peer assessment evokes in-depth reflection on learning (Hsiung, 2012; Chin \& Osborne, 2008).

It bears emphasizing that support for low-achieving students should not be overly demanding; lecturers should not be overly burdened with mobilizing the low achieving students to contend with complex tasks. College lecturers may avoid active teaching strategies that entail extensive preparation or leave insufficient time to cover the whole syllabus. SQG activities encourage students to play an active role in learning without imposing a special burden on the lecturer and without necessitating significant changes in course topics. This makes SQG a strong candidate for assimilation and adoption. In addition, SQG activities are well suited to college students who fixate on doing well on their exams. The creation of a question bank for exam preparation was the most important factor in mobilizing students to learn by generating, answering, and peer-assessing questions (Aflalo, 2018).

The contribution of SQG to the low-achieving group is especially important because these students are, by and large, the most prone to drop out of school. An improvement in their grades often means crossing from 'fail' to 'pass' in a given course. This transition, if made, reinforces their self-confidence, their belief in their ability to succeed, and their motivation - abetting the retention of students who might otherwise drop out (Respondek et al. 2019).

Most participants in the current study were first-year degree students. Students are particularly in need of support at this stage, in which they must adjust to unfamiliar learning environments, cope with challenging tasks, and surmount stresses occasioned by failure to satisfy requirements (Perry, Hall \& Ruthig. 2005). After experiencing failure, most first-year students report a decrease in their ability to continue being successful in their studies, in contrast to what they report after performing tasks successfully (Hall, 2008). The student dropout rate changes with each year of studies and is highest in the first year (Respondek et al. 2019; Alarcon \& Edwards, 2013). Therefore, a meaningful improvement in grades after SQG activities may enhance the low achieving students' confidence in scholastic success and reduce their risk of dropping out.

In this study, the highest-achieving students improved neither their overall grades nor their grades on higher-order questions after SQG. This is unsurprising because this group had less room for improvement to begin with. Nevertheless, it is also important to challenge these students with complex thinking tasks and to motivate them to contribute to the group's learning.

One of the limitations of this study is that the comparison between the first-term (pre-SQG) grade and the second-term (post-SQG) grade involved exams that covered different subject matter, as taught in each term. Different subject matter, even in the same discipline, may affect the student's degree of comprehension and ability to cope with exam questions. The alternative, however — comparing different students who study the same subject matter-would have created an even more significant research constraint due to student variance. Another limitation was the relatively short duration of the SQG experience. A lengthier and more intensive activity might have yielded a broader improvement in grades.

In sum, mobilizing students on different levels to cope successfully with learning at a higher-order of thinking is a cardinal issue in research on teaching and learning. SQG activity is a constructive learning and teaching strategy that abets the advancement of low- and intermediate-achieving students in particular. These findings may contribute to reassessing the widely held belief among teachers that underachieving students cannot handle higher-order tasks - a belief that thwarts these students' progress and adversely affects the narrowing of disparities and the assurance of equal opportunity. Practically speaking, the SQG model may be integrated into almost every discipline taught at the college level and need not be limited to preservice science teachers. The more such activities are integrated into courses, the more meaningful their contribution to low-achieving students will be, enhancing their ability to cope with academic studies. 
Conflict of Interest Statement: No potential conflict of interest.

\section{References}

Aflao, E. (2018, April). Students Generating Questions as a Way of learning. Active Learning in Higher Education, in Press. https://doi.org/10.1177/1469787418769120

Alarcon, G. M., \& Edwards, J. M. (2013). Ability and motivation: Assessing individual factors that contribute to university retention. Journal of Educational Psychology, 105(1), 129-137. https://doi.org/10.1037/a0028496

Anderson, L. W., Krathwohl, D. R., Airasian, P. W., Cruikshank, K. A., Mayer, R. E., Pintrich, P. R., ... Wittrock, M. C. (2001). A taxonomy for learning, teaching, and assessing: A revision of bloom's taxonomy of educational objectives (abridged edition). White Plains, NY: Longman.

Bloom, B. S. (1956). Taxonomy of Educational Objectives: The Classification of Educational Goals (Handbook 1: Cognitive Domain). New York: Longmans, Green and Co.

Bransford, J. D., Brown, A. L., \& Cocking, R. R. (2000). How people learn. Washington, DC: National Academy Press.

Bruer, J. T. (1993). Schools for thought. Cambridge, MA: Mit Press. https://doi.org/10.7551/mitpress/6052.001.0001

Chin, C., \& Brown, D. E. (2002). Student-generated questions: A meaningful aspect of learning in science. International Journal of Science Education, 24(5), 521-549. https://doi.org/10.1080/09500690110095249

Chin, C., \& Osborne, J. (2008). Students' questions: A potential resource for teaching and learning science. Studies in Science Education, 44(1), 1-39. https://doi.org/10.1080/03057260701828101

Chiu, P. H. P., \& Cheng, S. H. (2017). Effects of active learning classrooms on student learning: A two-year empirical investigation on student perceptions and academic performance. Higher Education Research \& Development, 36(2), 269-279. https://doi.org/10.1080/07294360.2016.1196475

Dillon, J. T. (1988). The remedial status of student questioning. Journal of Curriculum Studies, 20(3), 197-210. https://doi.org/10.1080/0022027880200301

Dori, Y. J., \& Herscovitz, O. (1999). Question-posing capability as an alternative evaluation method: Analysis of an environmental case study. Journal of Research in Science Teaching: The Official Journal of the National Association for Research in Science Teaching, 36(4), 411-430. https://doi.org/10.1002/(SICI)1098-2736(199904)36:4<411::AID-TEA2>3.0.CO;2-E

Hacker, D. J., Bol, L., Horgan, D. D., \& Rakow, E. A. (2000). Test prediction and performance in a classroom context. Journal of Educational Psychology, 92(1), 160-170. https://doi.org/10.1037/0022-0663.92.1.160

Hall, N. C. (2008). Self-regulation of primary and secondary control in achievement settings: A process model. Journal of Social and Clinical Psychology, 27(10), 1126-1164. https://doi.org/10.1521/jscp.2008.27.10.1126

Hardy, J., Bates, S. P., Casey, M. M., Galloway, K. W., Galloway, R. K., Kay, A. E., . . McQueen, H. A. (2014). Student-generated content: Enhancing learning through sharing multiple-choice questions. International Journal of Science Education, 36(13), 2180-2194. https://doi.org/10.1080/09500693.2014.916831

Hsiung, C. M. (2012). The effectiveness of cooperative learning. Journal of Engineering Education, 101(1), 119-137. https://doi.org/10.1002/j.2168-9830.2012.tb00044.x

Kay, A. E., Hardy, J., \& Galloway, R. K. (2020). Student use of PeerWise: A multi-institutional, multidisciplinary evaluation. British Journal of Educational Technology, 51(1), 23-35. https://doi.org/10.1111/bjet.12754

Kaya, S. (2015). The effect of the type of achievement grouping on students' question generation in science. Australian Educational Researcher, 42(4), 429-441. https://doi.org/10.1007/s13384-014-0164-x

Kelley, M. R., Chapman-Orr, E., Calkins, S., \& Lemke, R. J. (2019). Generation and retrieval practice effects in the classroom using PeerWise. Teaching of Psychology, 46(2), 121-126. https://doi.org/10.1177/0098628319834174

Kiuhara, S. A., Gillespie Rouse, A., Dai, T., Witzel, B. S., Morphy, P., \& Unker, B. (2020). Constructing written arguments to develop fraction knowledge. Journal of Educational Psychology, 112(3), 584-607. https://doi.org/10.1037/edu0000391

Koch, A., \& Eckstein, S. G. (1991). Improvement of reading comprehension of physics texts by students' question formulation. International Journal of Science Education, 13(4), 473-485. 
https://doi.org/10.1080/0950069910130410

Kogan, M., \& Laursen, S. L. (2014). Assessing long-term effects of inquiry-based learning: A case study from college mathematics. Innovative Higher Education, 39(3), 183-199. https://doi.org/10.1007/s10755-013-9269-9

Middlecamp, C. H., \& Nickel, A. L. (2005). Doing science and asking questions II: An exercise that generates questions. Journal of Chemical Education, 82(8), 6-1181. https://doi.org/10.1021/ed082p1181

Nguyen, L. T., \& Ikeda, M. (2015). The effects of ePortfolio-based learning model on student self-regulated learning. Active Learning in Higher Education, 16(3), 197-209. https://doi.org/10.1177/1469787415589532

Nystrand, M., Wu, L. L., Gamoran, A., Zeiser, S., \& Long, D. A. (2003). Questions in time: Investigating the structure and dynamics of unfolding classroom discourse. Discourse Processes, 35(2), 135-198. https://doi.org/10.1207/S15326950DP3502_3

Offerdahl, E. G., \& Montplaisir, L. (2014). Student-generated reading questions: Diagnosing student thinking with diverse formative assessments. Biochemistry and Molecular Biology Education, 42(1), 29-38. https://doi.org/10.1002/bmb.20757

Papinczak, T., Peterson, R., Babri, A. S., Ward, K., Kippers, V., \& Wilkinson, D. (2012). Using student-generated questions for student-centred assessment. Assessment \& Evaluation in Higher Education, 37(4), 439-452. https://doi.org/10.1080/02602938.2010.538666

Perry, R. P., Hall, N. C., \& Ruthig, J. C. (2005). Perceived (academic) control and scholastic attainment in higher education. In J. C. Smart (Ed.), Higher education: Handbook of theory and research (Vol. XX, pp. 363-436). Great Britain: Springer. https://doi.org/10.1007/1-4020-3279-X_7

Proctor, B. E., Prevatt, F., Adams, K., Hurst, A., \& Petscher, Y. (2006). Study skills profiles of normal-achieving and academically-struggling college students. Journal of College Student Development, 47(1), 37-51. https://doi.org/10.1353/csd.2006.0011

Raes, A., Schellens, T., \& De Wever, B. (2014). Web-based collaborative inquiry to bridge gaps in secondary science education. Journal of the Learning Sciences, 23(3), 316-347. https://doi.org/10.1080/10508406.2013.836656

Respondek, L., Seufert, T., Hamm, J. M., \& Nett, U. E. (2019). Linking changes in perceived academic control to university dropout and university grades: A longitudinal approach. Journal of Educational Psychology. https://doi.org/10.1037/edu0000388

Rothstein, D., \& Santana, L. (2011). Make just one change: Teach students to ask their own questions. Harvard Education Press.

Shepard, L. A. (1991). Psychometricians' beliefs about learning. Educational Researcher, 20(7), 2-16. https://doi.org/10.3102/0013189X020007002

Shodell, M. (1995). The question-driven classroom: Student questions as course curriculum in biology. The American Biology Teacher, 57(5), 278-281. https://doi.org/10.2307/4449992

So, H., Seah, L. H., \& Toh-Heng, H. L. (2010). Designing collaborative knowledge building environments accessible to all learners: Impacts and design challenges. Computers \& Education, 54(2), 479-490. https://doi.org/10.1016/j.compedu.2009.08.031

Stefanou, C., Stolk, J. D., Prince, M., Chen, J. C., \& Lord, S. M. (2013). Self-regulation and autonomy in problem-and project-based learning environments. Active Learning in Higher Education, 14(2), 109-122. https://doi.org/10.1177/1469787413481132

Stevens, E. A., Murray, C. S., Fishstrom, S., \& Vaughn, S. (2020). Using question generation to improve reading comprehension for Middle-Grade students. Journal of Adolescent \& Adult Literacy, 64(3), 311-322. https://doi.org/10.1002/jaal.1105

Teo, T. W., \& Goh Wee, P. J. (2019). Assessing lower track students' learning in science inference skills in singapore. Asia-Pacific Science Education, 5(1). https://doi.org/10.1186/s41029-019-0033-z

White, B. Y., \& Frederiksen, J. R. (1998). Inquiry, modeling, and metacognition: Making science accessible to all students. Cognition and Instruction, 16(1), 3-118. https://doi.org/10.1207/s1532690xci1601_2

Yang, Y., van Aalst, J., Chan, C. K., \& Tian, W. (2016). Reflective assessment in knowledge building by students with low academic achievement. International Journal of Computer-Supported Collaborative Learning, 11(3), 
281-311. https://doi.org/10.1007/s11412-016-9239-1

Yerrick, R. K. (2000). Lower track science students' argumentation and open inquiry instruction. Journal of $\begin{array}{lllll}\text { Research in } & \text { Science } & \text { Teaching, } & 37(8), & \text { 807-38. }\end{array}$ https://doi.org/10.1002/1098-2736(200010)37:8<807::AID-TEA4>3.0.CO;2-7

Yu, F. (2012). Learner-centered pedagogy adaptable and scaffolded learning space design-online student question-generation. Paper presented at the International Conference on Computers in Education 2012 Singapore, 26-30 November.

Yu, F., \& Chen, Y. (2014). Effects of student-generated questions as the source of online drill-and-practice activities on learning. British Journal of Educational Technology, 45(2), 316-329. https://doi.org/10.1111/bjet.12036

Yu, F., \& Liu, Y. (2008). The comparative effects of student question-posing and question-answering strategies on promoting college students' academic achievement, cognitive and metacognitive strategies use. Journal of Education and Psychology, 31(3), 25-52.

Zohar, A., \& Alboher Agmon, V. (2018). Raising test scores vs. teaching higher order thinking (HOT): Senior science teachers' views on how several concurrent policies affect classroom practices. Research in Science \& Technological Education, 36(2), 243-260. https://doi.org/10.1080/02635143.2017.1395332

Zohar, A., \& Dori, Y. J. (2003). Higher order thinking skills and low-achieving students: Are they mutually exclusive?. The Journal of the Learning Sciences, 12(2), 145-181. https://doi.org/10.1207/S15327809JLS1202_1

Zohar, A., Degani, A., \& Vaaknin, E. (2001). Teachers' beliefs about low-achieving students and higher order thinking. Teaching and Teacher Education, 17(4), 469-485. https://doi.org/10.1016/S0742-051X(01)00007-5 


\section{Appendix. The SQG Model}

A. In the fifth lesson of the second semester, the students were presented with examples of questions at various orders of thinking on a topic that had already been covered. Although their education courses had familiarized them with the concepts pertaining to the types of questions and Bloom's taxonomy, they had little experience in classifying questions. To simplify matters, they were presented with a two-group taxonomy: basic knowledge and memorization questions, and higher-order-thinking questions that included all other types of questions such as comprehension, application, and synthesis. The activity lasted around thirty minutes and ended with a homework assignment that students were to perform in pairs. The exercise, a course requirement, included generating three questions on the topic taught in class, including at least two questions of the transformation type. The students were instructed to upload the questions to the course website within a week and to answer and comment on questions generated by another pair of students.

B. In the seventh lesson, examples of the students' questions were presented and discussed in class, addressing the level and clarity of the questions as well as possible answers. The class activity lasted around forty minutes.

C. The last lesson in the second semester was devoted in its entirety to generating and answering questions by the students. At the beginning of the lesson, the students were told with emphasis that the activities in the lesson would help them to summarize and organize the material and would result in the construction of a question bank that would help them to review for the exam. Moreover, the sequence and nature of the activities, as detailed below, were briefly explained in advance:

- The teacher divided the class into four or five groups comprised of three or four students each, depending on the size of the class. Each group was heterogeneous in respect of its first-semester achievements, including students who earned high, mediocre, or poor grades.

- Each group was given one main topic among the topics studied during the second semester and was asked to generate five questions about it, including at least three transformation or higher-order-thinking questions. They were given forty minutes to generate the questions and were allowed to use materials from lectures, the course website, digital books, and various websites as aids.

- The teacher facilitated the groups during the SQG activity, mostly in the sense of helping them to generate the transformation questions and encouraging less-active students to participate. The group uploaded the questions to the course website only after the teacher approved them.

- When the forty minutes of question generation were up, each group received another group's questions and spent around thirty minutes answering them and also commenting on their level and clarity. The answers and the comments were then given to the group that generated the questions, which then checked the answers and read the comments on its questions.

- When the activity was over, a bank of around twenty-five questions covering all of the second-semester course topics was created and uploaded to the course website. Some 60 percent of the questions were of the higher-order-thinking type.

In sum, the three activities — question generation, question answering, and peer assessment- took place in the following sequence: (1) class discussion of the types of questions and their classification; (2) a homework assignment to generate, answer, and assess questions; (3) class discussion of the homework assignment; (4) a group activity in class to generate, answer, and peer-assess the questions; (5) creation of a question bank.

\section{Copyrights}

Copyright for this article is retained by the author(s), with first publication rights granted to the journal.

This is an open-access article distributed under the terms and conditions of the Creative Commons Attribution license (http://creativecommons.org/licenses/by/4.0/). 